\title{
Clinical indications for computed tomographic colonography: European Society of Gastrointestinal Endoscopy (ESGE) and European Society of Gastrointestinal and Abdominal Radiology (ESGAR) Guideline

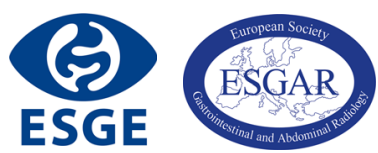

\author{
Cristiano Spada • Jaap Stoker • Onofre Alarcon - Federico Barbaro • Davide Bellini • \\ Michael Bretthauer • Margriet C. De Haan • Jean-Marc Dumonceau • Monika Ferlitsch • \\ Steve Halligan • Emma Helbren • Mikael Hellstrom • Ernst J. Kuipers • Philippe Lefere • \\ Thomas Mang • Emanuele Neri • Lucio Petruzziello • Andrew Plumb • Daniele Regge • \\ Stuart A. Taylor • Cesare Hassan • Andrea Laghi
}

Published online: 3 October 2014

(C) The Author(s) 2014. This article is published with open access at Springerlink.com

\begin{tabular}{|c|c|}
\hline Abbrevia & ons \\
\hline $\mathrm{CI}$ & confidence interval \\
\hline C-RADS & CT Colonography Reporting and Data System \\
\hline $\mathrm{CRC}$ & colorectal cancer \\
\hline $\mathrm{CT}$ & computed tomography \\
\hline CTC & computed tomographic colonography \\
\hline ESGAR & $\begin{array}{l}\text { European Society of Gastrointestinal and } \\
\text { Abdominal Radiology }\end{array}$ \\
\hline his is al & ial guideline of the European Society of Gastrointestinal \\
\hline Endoscopy & $\begin{array}{l}\text { SGE) and the European Society of Gastrointestinal and } \\
\text { diology (ESGAR) published in Endoscopy and European }\end{array}$ \\
\hline Radiology & ultaneously. It addresses the clinical indications for the use \\
\hline of comput & mographic colonography (CTC). A targeted literature \\
\hline $\begin{array}{l}\text { search was } \\
\text { CTC The }\end{array}$ & formed to evaluate the evidence supporting the use of \\
\hline $\begin{array}{l}\text { Evaluation } \\
\text { recommen }\end{array}$ & $\begin{array}{l}\text { RDE) system was adopted to define the strength of } \\
\text { ons and the quality of evidence. }\end{array}$ \\
\hline
\end{tabular}

Electronic supplementary material The online version of this article (doi:10.1007/s00330-014-3435-z) contains supplementary material, which is available to authorized users.

C. Spada $\cdot$ F. Barbaro $\cdot$ L. Petruzziello $\cdot$ C. Hassan

Digestive Endoscopy Unit, Catholic University, Rome, Italy

J. Stoker · M. C. De Haan

Department of Radiology, Academic Medical Center, University of Amsterdam, Amsterdam, The Netherlands

\section{O. Alarcon}

Department of Gastroenterology, Hospital Universitario de Canarias, Facultad de Medicina, Universidad de La Laguna, La Laguna, Tenerife, Spain

D. Bellini · A. Laghi

Department of Radiological Sciences, Oncology and Pathology,

Sapienza University of Rome; I.C.O.T. Hospital, Latina, Italy
ESGE European Society of Gastrointestinal Endoscopy

FIT fecal immunochemical test

FOBT fecal occult blood testing

GRADE Grading of Recommendations Assessment, Development and Evaluation

NPV negative predictive value

PEG polyethylene glycol

PPV positive predictive value
M. Bretthauer

Department of Health Economy and Health Management, University of Oslo, and Department of Transplantation Medicine,

Gastroenterology Unit, Oslo University Hospital, Oslo, Norway

J.-M. Dumonceau

Gedyt Endoscopy Center, Buenos Aires, Argentina

M. Ferlitsch

Department of Internal Medicine III, Division of Gastroenterology and Hepatology, Medical University of Vienna, Vienna, Austria

S. Halligan · E. Helbren · A. Plumb · S. A. Taylor Centre for Medical Imaging, University College London, London, UK 
RCT randomized controlled trial

SIGGAR Special Interest Group in Gastrointestinal and Abdominal Radiology

\section{Main recommendations}

1 ESGE/ESGAR recommend computed tomographic colonography (CTC) as the radiological examination of choice for the diagnosis of colorectal neoplasia. ESGE/ESGAR do not recommend barium enema in this setting (strong recommendation, high quality evidence).

2 ESGE/ESGAR recommend CTC, preferably the same or next day, if colonoscopy is incomplete. Delay of CTC should be considered following endoscopic resection. In the case of obstructing colorectal cancer, preoperative contrast-enhanced CTC may also allow location or staging of malignant lesions (strong recommendation, moderate quality evidence).

3 When endoscopy is contraindicated or not possible, ESGE/ESGAR recommend CTC as an acceptable and equally sensitive alternative for patients with symptoms suggestive of colorectal cancer (strong recommendation, high quality evidence).

4 ESGE/ESGAR recommend referral for endoscopic polypectomy in patients with at least one polyp $6 \mathrm{~mm}$ in diameter detected at CTC. CTC surveillance may be clinically considered if patients do not undergo polypectomy (strong recommendation, moderate quality evidence).

5 ESGE/ESGAR do not recommend CTC as a primary test for population screening or in individuals with a positive first-degree family history of colorectal cancer (CRC). However, it may be proposed as a CRC screening test on an individual basis providing the screenee is adequately informed about test characteristics, benefits, and risks (weak recommendation, moderate quality evidence).

\section{Hellstrom}

Department of Radiology, Sahlgrenska University Hospital and Sahlgrenska Academy at University of Gothenburg, Gothenburg, Sweden

\section{E. J. Kuipers}

Department of Gastroenterology and Hepatology, Erasmus MC

University Medical Center, Rotterdam, The Netherlands

\section{P. Lefere}

Virtual Colonoscopy Teaching Centre, Hooglede, Belgium

P. Lefere

AZ Delta, Roeselare, Belgium

\section{Introduction}

Colorectal cancer (CRC) is a major cause of morbidity and mortality $[1,2]$. CRC screening by fecal occult blood testing (FOBT) has been shown to reduce CRC mortality [3, 4], and is currently used in several European countries. Colonoscopy is highly effective for detecting advanced neoplasia, and endoscopic polypectomy reduces subsequent CRCspecific incidence and mortality [5]. In Europe, colonoscopy is mainly used to investigate FOBT-positive or symptomatic patients, or as a preventive strategy in those with increased CRC risk [6].

Computed tomographic colonography (CTC) is a minimally invasive imaging technique that is highly accurate for detecting colorectal cancer (CRC) and adenomatous polyps. The technique is standardized [7], and CTC is more easily performed than barium enema. Evidence-based data suggest that CTC is the natural replacement for barium enema and a complementary rather than an alternative examination to colonoscopy. However, the clinical scenarios for which CTC is indicated remain unclear. To address this uncertainty -20 years after the first presentation of CTC at a radiological meeting [8] - the European Society of Gastrointestinal Endoscopy (ESGE) and the European Society of Gastrointestinal and Abdominal Radiology (ESGAR) decided to produce a common guideline regarding indications for CTC in clinical practice. Technical and quality issues of CTC have been deliberately excluded from this work as these have already been discussed separately [7].

\section{Methods}

The ESGE and ESGAR commissioned this Guideline (chairs C.S. and A.L.) and invited the listed authors to participate in the development of the Guideline. The key questions were prepared by the coordinating team (C.S. and A.L.) and then approved by the other members (see Appendix e1, available

T. Mang

Department of Biomedical Imaging and Image-guided Therapy,

Medical University of Vienna, Vienna, Austria

E. Neri

Diagnostic and Interventional Radiology, University of Pisa, Pisa, Italy

D. Regge

Institute for Cancer Research and Treatment, Candiolo-Torino, Italy

C. Hassan $(\bowtie)$

Department of Gastroenterology, Ospedale Nuovo Regina

Margherita, Via Morosini 30, Rome 00100, Italy

e-mail: cesareh@hotmail.com 
online). The coordinating team convened subgroup task forces, each with one radiologist and one endoscopist lead, and allocated the key questions to these task forces.

Each task force performed a systematic literature search to prepare evidence-based statements on their assigned key questions. Medline, EMBASE and other databases were searched including the following search terms as minimum: colon, cancer or malignancy or neoplasm, and CTC. All articles investigating CTC in symptomatic or screening contexts were selected by inspecting the title and abstract. Hereditary colorectal syndromes were excluded. After further exploration of the content, each task force summarized the included articles in a table of evidence (see Appendix e2, available online). All selected articles were graded on level of evidence and strength of recommendation according to the GRADE system $[9,10]$. The literature searches were updated to September 2013.

Each task force prepared statements answering their assigned key questions. The statements were discussed subsequently and voted on during a face-to-face meeting of the whole group held on 1 October 2013. In May 2014, a draft prepared by the coordinating team was sent to all group members for comment. After agreement on a final version, the manuscript was reviewed by two experts selected by the ESGE and ESGAR Governing Boards and then submitted to the journals of ESGE and ESGAR.

This Guideline will be reviewed in 2019, or sooner if relevant new evidence becomes available. Any updates to the Guideline in the interim will be noted on the websites of ESGE (http://www.esge.com/esge-guidelines.html) and ESGAR (http://www.esgar.org).

\section{Recommendations and statements}

Evidence statements and recommendations are stated in italics, key evidence statements and recommendations are in bold.

\section{CT colonography (CTC) and diagnosis of colorectal neoplasia}

ESGE/ESGAR recommend computed tomographic colonography (CTC) as the radiological examination of choice for the diagnosis of colorectal neoplasia. ESGE/ESGAR do not recommend barium enema in this setting (strong recommendation, high quality evidence).

Computed tomographic colonography (CTC) can be considered to be the best radiological test for the diagnosis of colorectal cancer. Several randomized [11-13], multicenter $[14,15]$, and single-center trials [16-18], and meta-analyses [19-26], have shown that regarding accuracy for both colorectal cancer (CRC) and large/advanced polyps, CTC is similar to colonoscopy in symptomatic and asymptomatic patients and is clearly superior to barium enema [11]. In a recent randomized trial (the SIGGAR trial) $[11,13]$ comparing CTC with colonoscopy and barium enema, the detection rate for colorectal cancer or large polyps was significantly higher in patients assigned to CTC than in those assigned to barium enema $(7.3 \%$ vs $5.6 \%, P<0.039)$ but similar for colonoscopy and CTC (11\% for both procedures).

In a comparative study between colonoscopy and barium enema [27], the sensitivity and specificity of barium enema were respectively $38 \%$ and $86 \%$ for polyps of any size. In another publication [28], using a 5-mm threshold, per-patient sensitivity and specificity of barium enema were respectively $41 \%$ and $82 \%$; at a threshold greater than $10 \mathrm{~mm}$, these values were respectively $48 \%$ and $90 \%$.

In a meta-analysis comparing the performance of barium enema with CTC [29] for detection of colorectal polyps $\geq 6 \mathrm{~mm}$ in average risk and high risk patients, CTC was more specific and more sensitive than barium enema for large polyps $(\geq 10 \mathrm{~mm})$ and small polyps $(6-9 \mathrm{~mm})$, in both perpatient and per-polyp analysis. In the per-patient analysis, CTC showed an incremental diagnostic yield in sensitivity of $12.0 \%$ for polyps $\geq 10 \mathrm{~mm}$ and of $30.1 \%$ for polyps of $6-9$ $\mathrm{mm}$, and in specificity of $10.3 \%$ for polyps $\geq 10 \mathrm{~mm}$.

Apart from better diagnostic performance, CTC is more tolerable and acceptable to patients and delivers a lower effective radiation dose than barium enema [30].

\section{CT colonography following incomplete colonoscopy}

ESGE/ESGAR recommend CT colonography (CTC), preferably the same or next day, if colonoscopy is incomplete. Delay of CTC should be considered following endoscopic resection. In the case of obstructing colorectal cancer, preoperative contrast-enhanced CT colonography may also allow location or staging of malignant lesions. (strong recommendation, moderate quality evidence).

Incomplete colonoscopy has been reported to occur in $10 \%-15 \%$ of all colonoscopies [31, 32], and it has been associated with a higher risk of interval cancers in epidemiological studies [33]. Incomplete colonoscopy may be addressed by repetition of colonoscopy or by radiological procedures. Repeat colonoscopy is likely to be considered when the reason for the previous failure was inadequate bowel preparation $[34,35]$. On the other hand, radiological referral appears most frequently indicated in the case of difficult anatomy or patient intolerance [35]. Several studies [36-46] have investigated CTC as a completion procedure following incomplete colonoscopy. These studies show high technical feasibility, a relatively high diagnostic yield, and an adequate 
positive predictive value (PPV), especially at a $10-\mathrm{mm}$ threshold. However, none of the studies employed an independent reference standard for individuals with negative CTC findings, so that the accuracy of CTC in this setting is unknown. However, there is no apparent reason why the high accuracy shown by CTC in both asymptomatic and symptomatic settings, especially for large polyps or CRC, should not be extrapolated to those individuals with incomplete colonoscopy. For this reason, the superiority of CTC over barium enema recently shown in a large randomized study [11] should favor performance of CTC rather than barium enema following an incomplete colonoscopy.

Timing of CTC after incomplete colonoscopy

CTC after incomplete colonoscopy requires a different approach from primary CTC. When endoscopic biopsy has been done, CTC can be performed on the same day as the endoscopic procedure. An ultralow/low dose pre-CTC scan of the abdomen and pelvis before insertion of the rectal tube may rule out the presence of extraluminal gas that would indicate a colonoscopic perforation. In detail, in 262 patients undergoing CTC after incomplete colonoscopy, 2 perforations were detected $(0.8 \%, 95 \%$ confidence interval $[95 \% \mathrm{CI}] 0.1-2.7)$ [47]. In the case of endoscopic resection (i.e. polypectomy/ mucosectomy), it is prudent to consider an approximately 2week delay before performing CTC. However, there is little scientific evidence concerning the interval between endoscopic resection and subsequent CTC, thus for each case there should be a clinical discussion between the endoscopist and the radiologist. However, in a recent study on $65 \mathrm{CRC}$ patients with severe luminal narrowing after incomplete colonoscopy with either polypectomy or biopsy sampling, no extraluminal gas was detected at CTC within 24 hours [48]. Other evidence for the safety of radiologic imaging after endoscopic biopsy comes from barium enema studies, both experimental and clinical [49-52]. These studies concluded that in a nondiseased colon, barium enema could be performed immediately after endoscopic biopsy without any risk. In the case of endoscopic resection, barium enema could be performed without any risk after 6 days.

Incomplete colonoscopy due to obstructing CRC

Accurate preoperative assessment of the whole colon is required to exclude synchronous CRC. In a recent populationbased study of 13683 Dutch patients diagnosed with CRC, $3.9 \%$ were diagnosed with synchronous CRC, and in $34 \%$ of these cases the two tumors were located in different surgical segments [53]. These data were in line with those from a previous French study [54] and from other series [55]. Failure to detect synchronous cancer can increase morbidity, and one study has shown that intraoperative palpation can miss up to
$69 \%$ of synchronous malignancies $[56,57]$. Thus, preoperative whole-colon assessment is needed.

CTC appears to be an effective and safe choice when obstructing CRC prevents a complete endoscopic assessment or when cecal intubation fails for other reasons. A recent study including $286 \mathrm{CRC}$ cases after failed colonoscopy showed CTC negative predictive values (NPVs) of $100 \%$ and $97 \%$ for synchronous cancer and advanced neoplasia, respectively, in a preoperative setting [58]. This is in line with a previous systematic review, showing equivalent sensitivity of colonoscopy and CTC for established cancer [22], and in line with findings from similar cohort studies [44, 59-63].

\section{Patients with abdominal symptoms suggestive of colorectal cancer}

When endoscopy is contraindicated or not possible, ESGE/ESGAR recommend CT colonography (CTC) as an acceptable and equally sensitive alternative for patients with symptoms suggestive of colorectal cancer (strong recommendation, high quality evidence).

Patients with abdominal symptoms suggestive of colorectal cancer (CRC) require detailed investigation, since neither clinical examination nor fecal testing reliably excludes CRC [64]. The ideal test would also diagnose non-neoplastic conditions responsible for the symptoms (both within the colon and beyond it). Patient acceptability and safety are also important.

\section{Colorectal neoplasia}

In the SIGGAR trial no significant difference in the detection rates for large polyps ( $\geq 10 \mathrm{~mm}$ ) and for colorectal cancer was demonstrated between CTC and colonoscopy [13]. Furthermore, the crude pooled sensitivity of CTC for colorectal cancer in the studies of symptomatic patients was 96\% (169 out of 176 colorectal cancers detected) [13]. This is compatible with the $96.1 \%$ sensitivity of CTC for colorectal cancer that was reported in a meta-analysis [22] that included both screening and symptomatic/high risk patients. When large polyps ( $\geq 10 \mathrm{~mm}$ ) only were considered, per-patient sensitivity of CTC ranged from $82 \%$ to $92 \%$ in six meta-analyses that included screening, symptomatic, high risk, and FOBTpositive patients [19-21, 23, 25, 26]. In the studies specifically investigating symptomatic patients, pooled sensitivity for large $\geq 10$-mm lesions (excluding cancers) was $91.4 \%$ (53 of 58 patients).

These data suggest that CTC and colonoscopy have similar sensitivity for detecting CRC and large polyps in symptomatic patients. Small polyps $(6-9 \mathrm{~mm})$ and diminutive polyps $(\leq 5$ $\mathrm{mm}$ ) are less relevant in symptomatic patients, since they 
cannot explain the patient's symptoms. Nonetheless, the ability to opportunistically detect and remove early precursor lesions and perform histopathologic analysis of diagnosed CRC remains a potential advantage of colonoscopy over CTC.

\section{Colorectal non-neoplastic disease}

Abdominal symptoms may be due to non-neoplastic colonic conditions, for which both CTC and colonoscopy may be useful. Diverticulosis is more commonly demonstrated at CTC than colonoscopy [13, 65], although the relationship between diverticulosis and symptoms is less clear. Colonoscopy is more sensitive for the detection of colitis and anal pathology [13]; furthermore it offers the possibility of sampling tissue.

\section{Extracolonic findings}

CTC is an abdominal CT examination with the ability to detect extracolonic diseases. Although these extracolonic lesions may occasionally explain the symptoms, on the other hand, incidental findings that ultimately prove unimportant may prompt additional tests that are inconvenient, costly, and even harmful. Few studies of extracolonic findings focus specifically on symptomatic patients, in whom there is a higher prevalence of significant abnormality. The two largest series, of screening [66] and symptomatic [11, 13] patients, respectively reported $0.35 \%$ and $1.9 \%$ rates of extracolonic malignancy. Importantly, in the paired SIGGAR trials, at 3-year follow-up there was no significant difference in rates of extracolonic malignancy between the two arms of each of the trials (CTC vs. barium enema, and CTC vs. colonoscopy), although all arms showed rates significantly above rates expected for the general population. The latter observation may be explained by subsequent use of CT to investigate persistent symptoms in patients randomized to colonoscopy or barium enema, although this remains unproven.

\section{CT colonography and screening for colorectal cancer}

ESGE/ESGAR do not recommend CT colonography (CTC) as a primary test for population screening or in individuals with a positive first-degree family history of colorectal cancer (CRC). However, it may be proposed as a CRC screening test on an individual basis providing the screenee is adequately informed about test characteristics, benefits, and risks (weak recommendation, moderate quality evidence).
Accuracy of computed tomography colonoscopy (CTC)

To date, only guaiac FOBT (g-FOBT) and sigmoidoscopy have been shown to reduce CRC mortality, by $16 \%$ and $22 \%-31 \%$ respectively [67-69]. CTC has not been subjected to randomized trials with $\mathrm{CRC}$ incidence or mortality as end points. Therefore, the accuracy of CTC is used as a surrogate end point for CTC efficacy in a screening setting.

CTC accuracy in average risk screening populations has been investigated by a recent meta-analysis [24], which estimated per-patient sensitivity at $88 \%$ for advanced neoplasia $\geq 10 \mathrm{~mm}$. One further primary study published after this review, showed similar results [16]. In six screening studies, none of the 12 CRCs present were missed by CTC in average risk individuals [14, 16-18, 70-72]. Individuals with a positive family history of CRC or adenomas should be considered to be at high risk [73]. One recent cohort study showed a $89 \%$ sensitivity of CTC for advanced neoplasia $\geq 10 \mathrm{~mm}$ in this setting [74].

\section{CTC in screening: participation and yield}

The efficacy of a screening program not only depends on the diagnostic accuracy of the screening test that is used, but also on participation. This is illustrated by the results of a large population-based randomized screening trial performed in the Netherlands: participation rates for colonoscopy and CTC of $22 \%$ and $34 \%$, respectively, were reported, and detection rates for advanced neoplasia of 8.7 and 6.1 persons per 100 participants, respectively [12]. Despite the higher sensitivity of colonoscopy and the fact that CTC participants were only referred to colonoscopy if they had lesions $\geq 10 \mathrm{~mm}$ detected by CTC, the number of individuals per 100 invitees found to have advanced neoplasia was similar for both screening modalities, namely 1.9 (colonoscopy) versus 2.1 (CTC) per 100 invitees [12]. The poorer sensitivity of CTC compared with colonoscopy was countered by its approximately 1.5 times higher participation rate.

In the case of serrated adenomas the diagnostic yield of colonoscopy was 5 times higher than that of CTC. This is of particular importance, since approximately $10 \%-20 \%$ of CRC develops from the serrated pathway [75].

The diagnostic yield of CTC screening per 100 invitees would appear to be significantly higher than the yield of firstround g-FOBT, but similar to the yield of first-round flexible sigmoidoscopy screening (2.2 per 100 invitees) and fecal immunochemical testing (FIT) screening (2.0 per 100 invitees when using a cutoff of $50 \mathrm{ngHb} / \mathrm{mL}$ ) [76]. One should however bear in mind that FOBT/FIT screening is repeated at 2-year intervals, whereas 5-10year intervals are usually recommended for CTC and endoscopic screening. 


\section{Acceptability of CTC screening}

A recent meta-analysis included articles on preferences and differences in burden for both average risk and high risk individuals who had undergone CTC as well as colonoscopy (tandem design) [77]. Amongst the included studies, 3573 patients reported a preference for CTC, 927 showed a preference for colonoscopy, and 1116 showed no difference in preference.

In a Dutch population-based screening trial, almost half of the nonparticipants made an informed decision on participation as they were provided with adequate knowledge of CRC and CRC screening, and showed a positive attitude towards screening, but nevertheless declined participation, which suggested that additional barriers to participation were present [78]. The reasons cited for declining screening by colonoscopy or by CTC were similar overall [79]. However, colonoscopy invitees who declined most often mentioned 'unpleasantness of the examination' as their prime reason, while for CTC invitees 'no time/too much effort' and 'lack of symptoms' were most often cited. The last finding is consistent with the findings of the study of Ho et al., in which $38 \%$ did not participate in CTC screening because of procrastination and $12 \%$ because they were too busy [80].

As indicated above, most previous screening studies, using a tandem design to compare perceived acceptability and burden of the two techniques, showed a significant preference for CTC, with $46 \%$ to $95 \%$ of participants preferring CTC for future investigation $[17,81,82]$.

A recent Netherlands study performed within the population-based screening trial mentioned above showed that colonoscopy invitees expected the screening procedure and bowel preparation to be more burdensome than did CTC invitees [83]. CTC participants in the Dutch study however found their screening procedure slightly more burdensome than did colonoscopy participants. Colonoscopy participants gave higher burden scores to ingesting the bowel preparation, while CTC participants gave higher burden scores to related bowel movements (i.e. diarrhoea and bowel cramps). Although these differences were statistically significant, they were mostly small and thus the clinical relevance is limited for a clinical population, but more significant for a primary screening population. This is illustrated by the fact that intended participation in a subsequent screening round exceeded $90 \%$ for both colonoscopy and CTC.

\section{Safety of CTC screening}

\section{Adverse events}

The risk of major adverse events due to the CTC examination itself (including the bowel preparation) is low and presumed lower than for colonoscopy [13, 84]. Adverse events of CTC screening, however, should include events related to the entire episode, also including those related to any colonoscopy required to investigate CTC findings (e.g. post-polypectomy bleeding).

In a randomized trial comparing CTC with colonoscopy screening, serious adverse events were comparable for both procedures, ( $0.2 \%$ for CTC; $0.3 \%$ for colonoscopy) [12]. These rates are similar to adverse events observed in randomized trials of FOBT and of flexible sigmoidoscopy screening [85]. In a recent meta-analysis [86] on 103399 asymptomatic and symptomatic patients, the CTC perforation rate was estimated to be $0.04 \%$ overall; the rate was 19 -fold higher in symptomatic compared with screening individuals. The CTCinduced surgery rate was $0.008 \%$ and no CTC-related deaths were reported.

\section{Radiation risk in screening}

Radiation exposure at CTC is associated with a risk of cancer induction. This risk is relevant for all individuals but especially so in screening where benefit should clearly outweigh potential harm. The risk associated with ionizing radiation at a single CTC is very small and has been estimated as an absolute lifetime cancer risk of $0.14 \%$ for a 50 -year-old and $0.07 \%$ for a 70 -year-old, and can be reduced substantially with protocol optimization [87]. Another study reported a less than $0.2 \%$ increase of the lifetime cancer risk in individuals undergoing CTC screening every 5 years between the ages of 50 and 80 years [88].

A study compared the anticipated cancer induced versus anticipated cancer prevented by CTC screening using the effective dose of a screening study $(7 \mathrm{mSv}$ for men and $8 \mathrm{mSv}$ for women) [89]. In that study the radiation-related lifetime cancer risk for a single screening CTC was $0.06 \%$ for a 50-year-old person and decreased with age. The corresponding calculated benefit-risk ratio for a 50-year-old person ranged from $24: 1$ to $35: 1$ depending on the model used. A recent international survey reported that the effective dose of present day screening CTC was $4.4 \mathrm{mSv}$ [90], which is lower than used in the aforementioned study. Further dose reduction is possible with technical developments such as iterative reconstruction algorithms and lower tube voltage, leading to doses of $1 \mathrm{mSv}$ [91].

\section{Extracolonic findings}

Extracolonic findings are common at screening CTC and have been reported to occur in from one quarter to more than one half of screenees [92-97]. The incidence of extracolonic findings increases significantly with age; one study reported extracolonic findings in $55.4 \%$ of screenees younger than 65 years and in $74 \%$ of those 65 years or older [96]. The large 
majority of extracolonic findings are irrelevant and can be classified as such at CTC.

Work-up for (potentially) important extracolonic findings occurs in approximately $10 \%$ of cases [97-99]. The prevalence of extracolonic findings of moderate or high importance at CTC is commonly reported to be approximately $10 \%-15 \%$ of screenees [94, 95, 98, 99], although higher prevalence is occasionally reported $[92,100]$. This difference is partly caused by variation in the definition of moderate and high importance findings. The proportion of findings of high importance is mostly in the order of $2 \%-5 \%$ [95, 97, 99], and includes approximately $0.5 \%$ extracolonic cancers, of which renal cell cancer, lung cancer and lymphoma are most prevalent $[66,97,99,100]$, and are usually localized at the time of diagnosis [66]. Further important extracolonic findings include abdominal aortic aneurysms, adrenal masses, and nonmalignant renal masses.

The costs reported for the additional work-up of extracolonic findings vary substantially and are influenced by the definition of a relevant finding needing work-up and by which costs are included. It appears that the average additional cost for extracolonic findings at CTC is of the order of 20-50 USD averaged over all attendees [94-96, 100, 101]. No studies report costs that might be saved by earlier detection of disease.

$\mathrm{CTC}$ as a primary screening modality for CRC: conclusions

Primary CTC and colonoscopy screening have similar yields for advanced neoplasia per invitee. However, the impact of extracolonic findings, both medically and economically, remains unknown. Although radiation exposure is a drawback, this disadvantage seems to be overemphasised especially given the current reduction in radiation exposure with CTC. Probably the most important factor is the question of whether CTC screening is cost-effective, and this is still unanswered. Based on these considerations, CTC cannot at this stage be recommended as the primary test for population CRC screening or in individuals with a positive first-degree family history. However, it may be suggested as a CRC screening test on an individual basis, providing the screenees are adequately informed about test characteristics, benefits, and risks.

CTC within a screening program, following positive fecal testing with incomplete/unfeasible colonoscopy

ESGE/ESGAR strongly recommend CT colonography (CTC) in the case of a positive fecal occult blood or fecal immunochemical test with incomplete or unfeasible colonoscopy, within organized population screening programs (strong recommendation, low quality evidence).

Repeated annual or biennial screening for colorectal cancer (CRC) by guaiac-based fecal occult blood testing (FOBT) reduces disease-specific mortality by approximately $15 \%-$ $18 \%$ [102]. Results of similar repeated screening by means of fecal immunochemical testing (FIT) are awaited. It is assumed that the impact on CRC-related mortality will be considerably higher than with FOBT, because of the higher uptake of FIT testing, and the higher sensitivity for advanced colorectal lesions [103]. This is confirmed by modelling studies [104]. This benefit is contingent on confirmation and treatment of underlying cancer or adenoma after a positive result. Colonoscopy combines sensitive diagnosis with therapy by endoscopic resection and is therefore regarded as the preferred test.

Since most screenees testing FOBT/FIT-positive will not have advanced neoplasia, CTC has been investigated as a possible triage test to select patients with lesions only of greater size for colonoscopy or surgery. The sensitivity of CTC for adenomas $\geq 6 \mathrm{~mm}$ was above $85 \%$ in six studies $[15,25,105-108]$ and was over $90 \%$ for adenomas $\geq 10$ $\mathrm{mm}$, a finding confirmed by a meta-analysis published after our literature search [25]. A modelling study concluded that the use of CTC as an intermediate after positive FOBT/FIT can only be cost-effective if the costs of CTC were $\leq 43 \%$ of the costs of colonoscopy [109]. Furthermore, despite sensitivity exceeding $85 \%$, lesion prevalence is so high that NPV is less than might be expected, ranging from $85 \%$ to $95 \%$ in the studies included. These factors mean that CTC should not be offered routinely to those testing FOBT/FIT-positive, and colonoscopy is preferable.

Since CTC does have good diagnostic performance, it may be considered for those unwilling to undergo colonoscopy or in whom colonoscopy is unfeasible or incomplete, although screenees should be informed that sensitivity (particularly for smaller adenomas) is slightly inferior to that of colonoscopy. There is some evidence that offering CTC to those who decline colonoscopy increases uptake [110]. CTC is safe, and therefore may be preferable in those with contraindications to colonoscopy or judged particularly high risk, although observational data suggest absolute detection rates may be lower than in healthy screenees who are fit for colonoscopy [111]. Reasons for differences in detection rates are unknown and only speculative at this stage. If the difference is confirmed, and if it is due to suboptimal CTC practice (CTC technique and/or image interpretation), procedures for guaranteeing high quality of CTC exams within organized population screening programs will be necessary.

\section{CT colonography and surveillance}

Following curative-intent resection of colorectal cancer

ESGE/ESGAR suggest CT colonography (CTC) with intravenous contrast medium injection for surveillance after 
curative-intent resection of colorectal cancer only in patients in whom colonoscopy is unfeasible (weak recommendation, low quality evidence).

Patients with resected colorectal cancer are at a $30 \%$ risk of recurrence $[112,113]$ which can be either colonic or extracolonic. Local recurrence is less common for colonic than rectal cancers $[112,114,115]$. Recurrence can occur either at the site of anastomosis or near the site of the primary resection. In contrast, metachronous lesions are colorectal adenomas and cancers that develop subsequently to the index cancer and do not originate from it. Extracolonic recurrent disease comprises distant metastases in the liver, lung, peritoneum, etc. CTC for postoperative surveillance following potentially curative resection of colorectal carcinoma has the potential to combine both colonic and extracolonic examination, and is therefore an alternative to combined optical colonoscopy and contrast-enhanced abdominal CT [116].

By means of a literature review, we identified eight cohort studies investigating contrast-enhanced CTC as a surveillance tool after resection of colorectal cancer [116-123]. All of these studies demonstrated a high technical feasibility.

\section{Local recurrence and metachronous colorectal cancer}

In these studies, all local recurrent $(\mathrm{n}=65)$ and metachronous $(n=9)$ colonic cancers, were detected [116-123]. The largest study included 548 patients who had subsequent colonoscopy and pathologic confirmation of colonic lesions [116]. CTC sensitivity for anastomotic and metachronous recurrence was $100 \%$. Per-patient and per-lesion sensitivities for advanced neoplasia were $81.8 \%$ and $80.8 \%$, respectively, and for all adenomatous lesions they were $80.0 \%$ and $78.5 \%$, respectively [116]. NPVs for adenocarcinoma, advanced neoplasia, and all adenomatous lesions were $100 \%, 99.1 \%$, and $97.0 \%$, respectively. CTC enabled detection of clinically unsuspected metastatic disease in 11 patients, none of them having a cancerous lesion in the colon [116].

\section{CTC surveillance detection of adenoma/polyp}

In a study on 548 consecutive patients, without clinical or laboratory evidence of recurrence following curative-intent CRC, who underwent contrast-enhanced CTC and subsequent colonoscopy and pathologic confirmation of colonic lesions, CTC sensitivity for all adenomas of $80.0 \%$ (per-patient) and $78.5 \%$ (per-lesion) were reported [116]. Unfortunately, accuracy data for these lesions cannot be extracted from the other studies, because of the low number of patients with polypoid lesions, inconsistent or insufficient reporting on the detection/ presence of polyps/adenomas, and/or lack of histological polyp data that impeded any stratification and comparison of results [117-123].

\section{CTC following polypectomy}

ESGE/ESGAR suggest CT colonography (CTC) in patients with high risk polyps in surveillance after polypectomy only when colonoscopy is unfeasible (weak recommendation, low quality evidence).

The recent ESGE Guideline recommends endoscopic surveillance only for patients with high risk adenomatous lesions (adenomas with villous histology or high grade dysplasia or $\geq 10 \mathrm{~mm}$ in size, or $\geq 3$ adenomas) or serrated lesions $(\geq 10 \mathrm{~mm}$ in size, or any degree of cytological dysplasia) [124]. Colonoscopy is considered to be the method of choice for post-polypectomy surveillance, whose primary aim is to diagnose and remove polyps either missed at initial examination or newly developed during the time interval between the index and follow-up examination. However, compliance with colonoscopic surveillance is relatively low, ranging from $52 \%$ to $85 \%$, with the highest levels obtained in research settings [125-128]. Despite weak evidence supporting CTC for surveillance [15], in patients who are unwilling or unable to undergo colonoscopy, СTC is the best alternative because of its high sensitivity and NPV, outperforming barium enema [11, 22, 29].

\section{Safety of CT colonography}

ESGE/ESGAR state that CT colonography (CTC) is contraindicated in patients with active colonic inflammation and in those who have recently undergone colorectal surgery (strong recommendation, low quality evidence).

Despite being generally regarded as safer than colonoscopy [129], CTC has been shown to be associated with potentially serious adverse events, in particular perforation of the large bowel $[130,131]$. Acute abdominal conditions, for example diverticulitis or active inflammatory bowel disease (IBD), are absolute contraindications to CTC, because of the relatively high risk of complication [132], and CTC should be avoided [130]. Unfortunately, there are few studies supporting these strong recommendations. In a recent meta-analysis [86] including more than 100000 individuals, 28 colonic perforations were reported. Moreover, eight case reports - not included in the meta-analysis - detail CTC perforation [133-140]. These reports allow identification of some risk factors for perforation. Among the 36 patients with perforation, four $(11 \%)$ were affected by inflammatory bowel diseases, four had a known inguinal hernia, and in one case the perforation occurred after erroneous inflation of a rectal stump. Moreover, 
mural frailty during active inflammation or in the postoperative setting suggests that any procedure involving colonic distension entails a risk.

\section{Colonoscopy following CT colonography}

ESGE/ESGAR recommend referral for endoscopic polypectomy in patients with at least one polyp $\geq 6 \mathrm{~mm}$ in diameter detected at CT colonography (CTC). CTC surveillance may be clinically considered if patients do not undergo polypectomy (strong recommendation, moderate quality evidence).

Polyp size and risk of advanced neoplasia

\section{Diminutive polyps $(\leq 5 \mathrm{~mm})$}

Most colorectal lesions encountered at endoscopy are polyps $\leq 5 \mathrm{~mm}$ (i.e. diminutive) [141]. However, only a small proportion of these lesions meet histological criteria for advanced neoplasia. In detail, a recent systematic review of 28947 polyps found the frequency of advanced neoplasia to be $1.4 \%$ (408/28 947), while the risk of invasive cancer was $0.03 \%(10 / 31263)$ [142]. Little information is available regarding the natural history of untreated $\leq 5$-mm polyps. In two prospective Northern European endoscopic studies, Hoff et al. [143] and Hofstad et al. [144] followed up 194 diminutive and $253 \leq 9 \mathrm{~mm}$ polyps for 2 and 3 years, respectively. No diminutive polyp reached $>5 \mathrm{~mm}$ in size and only $0.5 \%$ of polyps $\leq 10 \mathrm{~mm}$ exceeded the 10 -mm threshold after 1 year; no cases of severe dysplasia or carcinoma were reported [143, 144]. Similar findings were reported by a Japanese study, in which only $2.9 \%$ of 408 subcentimetric lesions followed up for 43.1 months reached $\geq 10 \mathrm{~mm}$ size, without any invasive cancer occurring [145].

Small polyps (6-9 $\mathrm{mm})$

Overall, polyps of 6-9 $\mathrm{mm}$ (i.e. small polyps) represent about $15 \%$ of all the polyps detected during primary screening colonoscopy [141]. In a recent systematic review of 8605 polyps, the frequency of advanced neoplasia was $7.9 \%$, while the proportion with invasive cancer was $0.5 \%(10 / 8456]$ [142]. A retrospective analysis of 5124 individuals undergoing screening CTC confirmed a very low risk of advanced neoplasia and invasive cancer in 464 patients with polyps $6-$ $9 \mathrm{~mm}$ in size as the largest lesion, corresponding to a $3.9 \%$ and $0 \%$ risk, respectively [146].

Recently, the natural history of 6-9-mm polyps detected at CTC was addressed by a longitudinal study. Specifically, 243 adults with 306 small polyps detected by CTC underwent a second CTC after a 2-3-year follow-up [147]. Overall, 22\% polyps had progressed, with $6 \%$ exceeding $10 \mathrm{~mm}$. The odds ratio was 16 for advanced adenoma among polyps that had shown growth during surveillance compared with advanced adenoma among 6-9-mm polyps detected and removed at initial CTC and colonoscopy in a reference cohort. An absolute polyp volume of more than $180 \mathrm{~mm}^{3}$ at surveillance CTC was shown to predict advanced neoplasia (including one cancer) with a sensitivity of $92 \%$ ( 22 of 24 polyps), specificity of $94 \%$ ( 266 of 282 polyps), PPV of 58\% (22 of 38 polyps), and NPV of $99 \%$ (266 of 268 polyps).

Recently, factors that may predict advanced neoplasia within a subcentimeter polyp have been investigated. Kolligs et al. [148] applied a logistic regression model to a large retrospectively obtained cohort of 1077956 colonoscopies, in which 106270 small and 198954 diminutive lesions were removed. The risk of advanced neoplasia within subcentimetric lesions was associated with increasing age, male sex, polyp morphology, polyp multiplicity, and occult or overt blood in the stools.

\section{Large polyps $(\geq 10 \mathrm{~mm})$ and masses}

Overall, $\geq 10$-mm polyps (i.e. large polyps) represent about $10 \%$ of all polyps detected during primary screening colonoscopy [141]. In a previous systematic review, 73.5\% (1363/1855) of these polyps appeared to be advanced adenomas, the remainder being nonadenomatous [141]. The prevalence of invasive cancer has been recently addressed in large colonoscopic and CTC screening series, with reported ranges between $2 \%$ and $7 \%$ [146, 148, 149].

Same-day polypectomy

ESGE/ESGAR suggest same-day polypectomy as a possible option after CT colonography (CTC) performed with full bowel preparation. The implementation of this policy should take into account technical and logistical factors, including patient consent (weak recommendation, low quality evidence).

\section{Type of laxative used for CTC}

Bowel preparation for CTC usually includes a low residue diet and clear liquids for 24 hours or more, and a laxative preparation that may be either a "wet prep" (e.g. polyethylene glycol [PEG]) or "dry prep" (e.g. phosphosoda, magnesium citrate, etc). In the studies identified in the literature search for CTC and same-day colonoscopy, a range of different preparations was used, with approximately half using PEG, and the remaining using phosphosoda or a similar laxative. The rationale for laxative choice was rarely stated, although some studies documented that choice was based on that routinely 
used for colonoscopy by the host institution. Furthermore, although data were sometimes presented on quality of CTC preparation, few studies formally graded bowel cleansing during same-day colonoscopy.

One large study of same-day CTC and colonoscopy in 734 patients [105], investigated the quality of CTC imaging according to the CT Colonography Reporting and Data System (C-RADS) and graded the quality of bowel preparation at colonoscopy. Patients were prepared before CTC, with clear liquid during the preceding 24 hours, $30 \mathrm{ml}$ sodium phosphate and $20 \mathrm{mg}$ bisacodyl as laxatives, and oral barium and iodine agents for tagging. Only $3.1 \%$ of the procedures were classified as inadequate for CTC interpretation; in 20 of 23 cases this was due to insufficient insufflation. At colonoscopy, colonic preparation was classified by the endoscopist as excellent or good in $63 \%$ of patients, fair in $28 \%$, poor in $8.5 \%$, and inadequate in $0.5 \%$.

A minority of studies commented regarding the quality of preparation during colonoscopy, but provided little detailed information.

The fact that the literature is so sparse regarding quality of preparation during same-day colonoscopy does suggest that it is not a major issue. However it cannot be determined from the available literature which bowel preparation is preferred for same-day colonoscopy after CTC. Although the frequency and extent of retention of fecal material and fluids at CTC has been extensively studied, the effects of the various CTC preparation protocols on the performance of same-day colonoscopy is less well known.

\section{Laxative-free CTC}

Reduced bowel preparations at CTC are gaining popularity but may prevent same-day endoscopy (although minor fecal residue may be suctioned during colonoscopy). Our literature search found no information regarding the quality of sameday colonoscopy after same-day laxative-free CTC. However several studies have reported using additional bowel cleansing subsequent to laxative-free CTC when same-day colonoscopy is required. For example, in a study of 95 symptomatic patients undergoing reduced-laxative CTC, senna and $18 \mathrm{~g}$ magnesium citrate were used, with an additional $18 \mathrm{~g}$ of magnesium citrate after CTC but prior to colonoscopy [150]. Lefere et al. [151] compared standard bowel preparation, reduced bowel preparation, and oral barium for fecal tagging in 100 patients having CTC with same-day colonoscopy. In order to compensate for reduced bowel purgation, which may prohibit colonoscopy, PEG was administered after CTC, and colonoscopy performed 2-3 hours later.

\section{Fecal tagging}

Fecal tagging with oral barium or hyperosmolar/iso-osmolar iodine solutions or both is now considered mandatory for CTC [7]. Occasionally, concern has been raised that when barium is used, it may interfere with the diagnostic quality of same-day colonoscopy, potentially obscuring the endoscopic view by coating the colonic mucosa. Others have suggested that retained barium and iodine-based contrast agents are easily aspirated or flushed out of the way during endoscopy, and therefore are of no concern. Our literature search, including studies of same-day CTC and colonoscopy with or without fecal tagging, found little specific information on this issue. Frequency of incomplete colonoscopy was commonly cited, indicating causes such as tortuous bowel, pain, or strictures, but problems specifically related to fecal tagging were rarely mentioned.

Pickhardt et al. [18] analyzed 1233 asymptomatic patients undergoing CTC (with fecal and fluid tagging) and same-day colonoscopy with segmental unblinding. The quality of bowel preparation was not formally reported but only six of 1253 patients were excluded initially because of inadequate colonic preparation. Suboptimal colonoscopy quality was dismissed as a reason for missed adenomas since the colonoscopy completion rate was high at $99.4 \%$.

A similar tagging regimen was used in another large study, mentioned above, of same-day CTC and colonoscopy in a population at average or high risk of colorectal cancer [105]. The quality of CTC imaging was assessed by the radiologist according to the C-RADS system and the quality of bowel preparation at colonoscopy was graded by the endoscopist on a 5-point scale, from excellent to inadequate. At colonoscopy, $63 \%$ of cases were classified as excellent or good, $28 \%$ as fair, $8.5 \%$ as poor and $0.5 \%$ as inadequate. At CTC, 23 (3.1\% of the cases) cases were classified as $\mathrm{C} 0$, which includes preparation or insufflation that is inadequate for satisfactory interpretation; as noted above, 20 of the 23 cases were due to inadequate insufflation. These 23 cases were classified at colonoscopy as having excellent or good preparation in $65 \%$, fair in $30 \%$, and poor or inadequate in $5 \%$. There was no mention that tagging agents were a complicating factor at colonoscopy.

It can therefore be inferred indirectly from the relatively large number of comparative same-day CTC and conventional colonoscopy studies aimed at diagnostic accuracy, that fecal tagging likely does not negatively affect colonoscopy results.

Logistics of same-day colonoscopy

To provide same-day endoscopy after CTC, the indications and logistics concerning patient selection, timing, patient transportation, availability of endoscopists and endoscopy 
suites etc. must be pre-planned jointly by radiology and endoscopy units. This modality also requires that CTC findings are reviewed by a radiologist immediately in order to identify patients in whom same-day colonoscopy is needed, and in order to identify the rare but well-recognised perforations that occur during CTC.

When a lesion detected at CT colonography (CTC) is not confirmed by a high quality colonoscopy, ESGE/ESGAR recommend careful review of the CTC findings. In cases when post-colonoscopy radiological confidence for the presence of $a \geq 10-m m$ lesion remains high, early repetition of colonoscopy should be considered (weak recommendation, low quality evidence).

It is possible that colorectal lesions reported at CTC may not be detected at colonoscopy, either because they are CTC false positives or colonoscopic false negatives. Clinical consequences include progression of colonoscopic false-negative polyps towards invasive CRC or anxiety due to CTC falsepositive findings. In a recent prospective multicenter study of symptomatic patients, the PPV of CTC for large polyps was about $60 \%$, indicating that colonoscopic inability to confirm CTC findings occurs frequently [11]. The sensitivity of colonoscopy for $\geq 10$-mm polyps is higher [152], and may be presumed to be substantially increased when - as occurs in daily practice - the endoscopist is searching specifically for a CTC finding. Therefore, the possibility of missing large lesions at such colonoscopies may be considered too low to warrant a further endoscopic examination. However, it is well known that colonoscopy is not $100 \%$ sensitive even for large lesions that are present at CTC, a phenomenon that has been explained by the existence of colonoscopic "blind spots" [153]. Most post-colonoscopic interval cancers are related to missed rather than new lesions. In contrast to 6-9-mm polyps, the risk of established cancer in larger lesions is relevant [149]. Thus if, after negative colonoscopy findings, confidence in the CTC diagnosis remains high, an early repetition of colonoscopy should be considered, especially if the abnormality appears to be related to flexures or to be on the proximal side of colonic haustra.

ESGE guidelines represent a consensus of best practice based on the available evidence at the time of preparation. They may not apply in all situations and should be interpreted in the light of specific clinical situations and resource availability. Further controlled clinical studies may be needed to clarify aspects of these statements, and revision may be necessary as new data appear. Clinical consideration may justify a course of action at variance to these recommendations. ESGE guidelines are intended to be an educational device to provide information that may assist endoscopists in providing care to patients. They are not rules and should not be construed as establishing a legal standard of care or as encouraging, advocating, requiring, or discouraging any particular treatment.

\section{Competing interests None.}

Open Access This article is distributed under the terms of the Creative Commons Attribution Noncommercial License which permits any noncommercial use, distribution, and reproduction in any medium, provided the original author(s) and the source are credited.

\section{References}

1. Edwards BK, Ward E, Kohler BA et al (2010) Annual report to the nation on the status of cancer, 1975-2006, featuring colorectal cancer trends and impact of interventions (risk factors, screening, and treatment) to reduce future rates. Cancer 116:544-573

2. Ferlay J, Autier P, Boniol M et al (2007) Estimates of the cancer incidence and mortality in Europe in 2006. Ann Oncol 18:581-592

3. Towler BP, Irwig L, Glasziou P et al (2000) Screening for colorectal cancer using the faecal occult blood test, hemoccult. Cochrane Database Syst Rev 2, CD001216. doi:10.1002/14651858.CD001216

4. Hewitson P, Glasziou P, Watson E et al (2008) Cochrane systematic review of colorectal cancer screening using the fecal occult blood test (hemoccult): an update. Am J Gastroenterol 103:1541-1549

5. Zauber AG, Winawer SJ, O'Brien MJ et al (2012) Colonoscopic polypectomy and long-term prevention of colorectal-cancer deaths. N Engl J Med 366:687-696

6. Rembacken B, Hassan C, Riemann JF et al (2012) Quality in screening colonoscopy: position statement of the European Society of Gastrointestinal Endoscopy (ESGE). Endoscopy 44: 957-968

7. Neri E, Halligan S, Hellstrom M et al (2013) The second ESGAR consensus statement on CT colonography. Eur Radiol 23:720-729

8. Vining D, Galfand D, Bechtold R (1994) Technical feasibility of colon imaging with helical CT. AJR Am J Roentgenol 162:104

9. Atkins D, Best D, Briss PA et al (2004) Grading quality of evidence and strength of recommendations. BMJ 328:1490

10. Dumonceau JM, Hassan C, Riphaus A et al (2012) European Society of Gastrointestinal Endoscopy (ESGE) Guideline Development Policy. Endoscopy 44:626-629

11. Halligan S, Wooldrage K, Dadswell E et al (2013) Computed tomographic colonography versus barium enema for diagnosis of colorectal cancer or large polyps in symptomatic patients (SIGGAR): a multicentre randomised trial. Lancet 381:1185-1193

12. Stoop EM, de Haan MC, de Wijkerslooth TR et al (2012) Participation and yield of colonoscopy versus non-cathartic CT colonography in population-based screening for colorectal cancer: a randomised controlled trial. Lancet Oncol 13:55-64

13. Atkin W, Dadswell E, Wooldrage K et al (2013) Computed tomographic colonography versus colonoscopy for investigation of patients with symptoms suggestive of colorectal cancer (SIGGAR): a multicentre randomised trial. Lancet 381:1194-1202

14. Johnson CD, Chen MH, Toledano AY et al (2008) Accuracy of CT colonography for detection of large adenomas and cancers. N Engl $\mathrm{J}$ Med 359:1207-1217

15. Regge D, Laudi C, Galatola G et al (2009) Diagnostic accuracy of computed tomographic colonography for the detection of advanced neoplasia in individuals at increased risk of colorectal cancer. JAMA 301:2453-2461

16. Lefere P, Silva C, Gryspeerdt S et al (2013) Teleradiology based CT colonography to screen a population group of a remote island; at average risk for colorectal cancer. Eur J Radiol 82:e262-267

17. Graser A, Stieber P, Nagel D et al (2009) Comparison of CT colonography, colonoscopy, sigmoidoscopy and faecal occult blood tests for the detection of advanced adenoma in an average risk population. Gut 58:241-248 
18. Pickhardt PJ, Choi JR, Hwang I et al (2003) Computed tomographic virtual colonoscopy to screen for colorectal neoplasia in asymptomatic adults. N Engl J Med 349:2191-2200

19. Sosna J, Morrin MM, Kruskal JB et al (2003) CT colonography of colorectal polyps: a metaanalysis. AJR Am J Roentgenol 181:15931598

20. Chaparro M, Gisbert JP, Del Campo L et al (2009) Accuracy of computed tomographic colonography for the detection of polyps and colorectal tumors: a systematic review and meta-analysis. Digestion 80:1-17

21. Mulhall BP, Veerappan GR, Jackson JL (2005) Meta-analysis: computed tomographic colonography. Ann Intern Med 142:635650

22. Pickhardt PJ, Hassan C, Halligan S et al (2011) Colorectal cancer: CT colonography and colonoscopy for detection-systematic review and meta-analysis. Radiology 259:393-405

23. Halligan S, Altman DG, Taylor SA et al (2005) CT colonography in the detection of colorectal polyps and cancer: systematic review, meta-analysis, and proposed minimum data set for study level reporting. Radiology 237:893-904

24. de Haan MC, van Gelder RE, Graser A et al (2011) Diagnostic value of CT-colonography as compared to colonoscopy in an asymptomatic screening population: a meta-analysis. Eur Radiol 21:1747-1763

25. Plumb AA, Halligan S, Pendse DA et al (2014) Sensitivity and specificity of CT colonography for the detection of colonic neoplasia after positive faecal occult blood testing: systematic review and meta-analysis. Eur Radiol 24:1049-1058

26. Rosman AS, Korsten MA (2007) Meta-analysis comparing CT colonography, air contrast barium enema, and colonoscopy. Am J Med 120:203-210.e204

27. Winawer SJ, Stewart ET, Zauber AG et al (2000) A comparison of colonoscopy and double-contrast barium enema for surveillance after polypectomy. National Polyp Study Work Group. N Engl J Med 342:1766-1772

28. Rockey DC, Paulson E, Niedzwiecki D et al (2005) Analysis of air contrast barium enema, computed tomographic colonography, and colonoscopy: prospective comparison. Lancet 365:305-311

29. Sosna J, Sella T, Sy O et al (2008) Critical analysis of the performance of double-contrast barium enema for detecting colorectal polyps $>$ or $=6 \mathrm{~mm}$ in the era of CT colonography. AJR Am J Roentgenol 190:374-385

30. Neri E, Faggioni L, Cerri F et al (2010) CT colonography versus double-contrast barium enema for screening of colorectal cancer: comparison of radiation burden. Abdom Imaging 35:596-601

31. Shah HA, Paszat LF, Saskin R et al (2007) Factors associated with incomplete colonoscopy: a population-based study. Gastroenterology 132:2297-2303

32. Aslinia F, Uradomo L, Steele A et al (2006) Quality assessment of colonoscopic cecal intubation: an analysis of 6 years of continuous practice at a university hospital. Am J Gastroenterol 101:721-731

33. Baxter NN, Sutradhar R, Forbes SS et al (2011) Analysis of administrative data finds endoscopist quality measures associated with postcolonoscopy colorectal cancer. Gastroenterology 140:65-72

34. Hassan C, Bretthauer M, Kaminski MF et al (2013) Bowel preparation for colonoscopy: European Society of Gastrointestinal Endoscopy (ESGE) guideline. Endoscopy 45:142-150

35. Gawron AJ, Veerappan A, McCarthy ST et al (2013) Impact of an incomplete colonoscopy referral program on recommendations after incomplete colonoscopy. Dig Dis Sci 58:1849-1855

36. Pullens HJ, van Leeuwen MS, Laheij RJ et al (2013) CTcolonography after incomplete colonoscopy: what is the diagnostic yield? Dis Colon Rectum 56:593-599

37. Salamone I, Buda C, Arcadi T et al (2011) Role of virtual colonoscopy following incomplete optical colonoscopy: our experience. G Chir 32:388-393
38. Neerincx M, Terhaar sive Droste JS, Mulder CJ et al (2010) Colonic work-up after incomplete colonoscopy: significant new findings during follow-up. Endoscopy 42:730-735

39. Iafrate F, Hassan C, Zullo A et al (2008) CT colonography with reduced bowel preparation after incomplete colonoscopy in the elderly. Eur Radiol 18:1385-1395

40. Copel L, Sosna J, Kruskal JB et al (2007) CT colonography in 546 patients with incomplete colonoscopy. Radiology 244:471-478

41. Morrin MM, Kruskal JB, Farrell RJ et al (1999) Endoluminal CT colonography after an incomplete endoscopic colonoscopy. AJR Am J Roentgenol 172:913-918

42. Yucel C, Lev-Toaff AS, Moussa N et al (2008) CT colonography for incomplete or contraindicated optical colonoscopy in older patients. AJR Am J Roentgenol 190:145-150

43. Macari M, Berman P, Dicker M et al (1999) Usefulness of CT colonography in patients with incomplete colonoscopy. AJR Am J Roentgenol 173:561-564

44. Neri E, Giusti P, Battolla L et al (2002) Colorectal cancer: role of CT colonography in preoperative evaluation after incomplete colonoscopy. Radiology 223:615-619

45. Luo M, Shan H, Zhou K (2002) CT virtual colonoscopy in patients with incomplete conventional colonoscopy. Chin Med J 115:10231026

46. Lai C, Sammour T, Roadley G et al (2009) CT colonography in a rural New Zealand hospital. N Z Med J 122:67-73

47. Hough DM, Kuntz MA, Fidler JL et al (2008) Detection of occult colonic perforation before CT colonography after incomplete colonoscopy: perforation rate and use of a low-dose diagnostic scan before CO2 insufflation. AJR Am J Roentgenol 191:1077-1081

48. Kim SY, Park SH, Choi EK et al (2008) Automated carbon dioxide insufflation for CT colonography: effectiveness of colonic distention in cancer patients with severe luminal narrowing. AJR Am J Roentgenol 190:698-706

49. Maglinte DD, Strong RC, Strate RW et al (1982) Barium enema after colorectal biopsies: experimental data. AJR Am J Roentgenol 139:693-697

50. Harned RK, Williams SM, Maglinte DD et al (1985) Clinical application of in vitro studies for barium-enema examination following colorectal biopsy. Radiology 154:319-321

51. Harned RK, Consigny PM, Cooper NB et al (1982) Barium enema examination following biopsy of the rectum or colon. Radiology 145:11-16

52. Wytock DH, Baybick J (1987) Depth of colorectal biopsies with proctoscopic forceps. Gastrointest Endosc 33:15-17

53. Mulder SA, Kranse R, Damhuis RA et al (2011) Prevalence and prognosis of synchronous colorectal cancer: a Dutch populationbased study. Cancer Epidemiol 35:442-447

54. Latournerie M, Jooste V, Cottet V et al (2008) Epidemiology and prognosis of synchronous colorectal cancers. Br J Surg 95:15281533

55. Kim MS, Park YJ (2007) Detection and treatment of synchronous lesions in colorectal cancer: the clinical implication of perioperative colonoscopy. World J Gastroenterol 13:4108-4111

56. Heald RJ, Bussey HJ (1975) Clinical experiences at St. Mark's Hospital with multiple synchronous cancers of the colon and rectum. Dis Colon Rectum 18:6-10

57. Achiam MP, Burgdorf SK, Wilhelmsen M et al (2009) Inadequate preoperative colonic evaluation for synchronous colorectal cancer. Scand J Surg 98:62-67

58. Park SH, Lee JH, Lee SS et al (2012) CT colonography for detection and characterisation of synchronous proximal colonic lesions in patients with stenosing colorectal cancer. Gut 61:1716-1722

59. Leksowski K, Rudzinska M, Rudzinski J (2011) Computed tomographic colonography in preoperative evaluation of colorectal tumors: a prospective study. Surg Endosc 25:2344-2349 
60. Kim JH, Kim WH, Kim TI et al (2007) Incomplete colonoscopy in patients with occlusive colorectal cancer: usefulness of CT colonography according to tumor location. Yonsei Med J 48:934 941

61. Galia M, Midiri M, Carcione A et al (2001) [Usefulness of CT colonography in the preoperative evaluation of patients with distal occlusive colorectal carcinoma]. [Article in Italian.]. Radiol Med 101:235-242

62. Fenlon HM, McAneny DB, Nunes DP et al (1999) Occlusive colon carcinoma: virtual colonoscopy in the preoperative evaluation of the proximal colon. Radiology 210:423-428

63. Coccetta M, Migliaccio C, La Mura F et al (2009) Virtual colonoscopy in stenosing colorectal cancer. Ann Surg Innov Res 3:11

64. Jellema P, van der Windt DA, Bruinvels DJ et al. Value of symptoms and additional diagnostic tests for colorectal cancer in primary care: systematic review and meta-analysis. BMJ 2010; 340:

65. White TJ, Avery GR, Kennan N et al (2009) Virtual colonoscopy vs conventional colonoscopy in patients at high risk of colorectal cancer - a prospective trial of 150 patients. Colorectal Dis 11: 138-145

66. Pickhardt PJ, Kim DH, Meiners RJ et al (2010) Colorectal and extracolonic cancers detected at screening CT colonography in 10, 286 asymptomatic adults. Radiology 255:83-88

67. Heresbach D, Manfredi S, D'Halluin PN et al (2006) Review in depth and meta-analysis of controlled trials on colorectal cancer screening by faecal occult blood test. Eur J Gastroenterol Hepatol $18: 427-433$

68. Atkin WS, Edwards R, Kralj-Hans I et al (2010) Once-only flexible sigmoidoscopy screening in prevention of colorectal cancer: a multicentre randomised controlled trial. Lancet 375:1624-1633

69. Segnan N, Armaroli P, Bonelli L et al (2011) Once-only sigmoidoscopy in colorectal cancer screening: follow-up findings of the Italian Randomized Controlled Trial - SCORE. J Natl Cancer Inst 103:1310-1322

70. Kim YS, Kim N, Kim SH et al (2008) The efficacy of intravenous contrast-enhanced 16-raw multidetector CT colonography for detecting patients with colorectal polyps in an asymptomatic population in Korea. J Clin Gastroenterol 42:791-798

71. Macari M, Bini EJ, Jacobs SL et al (2004) Colorectal polyps and cancers in asymptomatic average-risk patients: evaluation with $\mathrm{CT}$ colonography. Radiology 230:629-636

72. Pickhardt PJ, Choi JR, Hwang I et al (2004) Nonadenomatous polyps at CT colonography: prevalence, size distribution, and detection rates. Radiology 232:784-790

73. Johns LE, Houlston RS (2001) A systematic review and metaanalysis of familial colorectal cancer risk. Am J Gastroenterol 96: 2992-3003

74. Fini L, Laghi L, Hassan C et al (2014) Noncathartic CT colonography to screen for colorectal neoplasia in subjects with a family history of colorectal cancer. Radiology 270:784-790

75. Leggett B, Whitehall V (2010) Role of the serrated pathway in colorectal cancer pathogenesis. Gastroenterology 138: $2088-2100$

76. Hol L, Wilschut JA, van Ballegooijen M et al (2009) Screening for colorectal cancer: random comparison of guaiac and immunochemical faecal occult blood testing at different cut-off levels. Br J Cancer 100:1103-1110

77. Lin OS, Kozarek RA, Gluck M et al (2012) Preference for colonoscopy versus computerized tomographic colonography: a systematic review and meta-analysis of observational studies. J Gen Intern Med 27:1349-1360

78. de Haan MC, de Wijkerslooth TR, Stoop E et al (2013) Informed decision-making in colorectal cancer screening using colonoscopy or CT-colonography. Patient Educ Couns 91:318-325

79. de Wijkerslooth TR, de Haan MC, Stoop EM et al (2012) Reasons for participation and nonparticipation in colorectal cancer screening: a randomized trial of colonoscopy and CT colonography. Am J Gastroenterol 107:1777-1783

80. Ho W, Broughton DE, Donelan K et al (2010) Analysis of barriers to and patients' preferences for CT colonography for colorectal cancer screening in a nonadherent urban population. AJR Am J Roentgenol 195:393-397

81. Pooler BD, Baumel MJ, Cash BD et al (2012) Screening CT colonography: multicenter survey of patient experience, preference, and potential impact on adherence. AJR Am J Roentgenol 198: 1361-1366

82. Moawad FJ, Maydonovitch CL, Cullen PA et al (2010) CT colonography may improve colorectal cancer screening compliance. AJR Am J Roentgenol 195:1118-1123

83. de Wijkerslooth TR, de Haan MC, Stoop EM et al (2012) Burden of colonoscopy compared to non-cathartic CT-colonography in a colorectal cancer screening programme: randomised controlled trial. Gut 61:1552-1559

84. Pendse DA, Taylor SA (2013) Complications of CT colonography: a review. Eur J Radiol 82:1159-1165

85. Holme O, Bretthauer M, Fretheim A et al (2013) Flexible sigmoidoscopy versus faecal occult blood testing for colorectal cancer screening in asymptomatic individuals. Cochrane Database Syst Rev 9, CD009259

86. Bellini D, Rengo M, De Cecco CN et al (2014) Perforation rate in CT colonography: a systematic review of the literature and metaanalysis. Eur Radiol 24:1487-1496

87. Brenner DJ, Elliston CD (2004) Estimated radiation risks potentially associated with full-body CT screening. Radiology 232:735-738

88. Perisinakis K, Seimenis I, Tzedakis A et al (2012) Screening computed tomography colonography with 256-slice scanning: should patient radiation burden and associated cancer risk constitute a major concern? Invest Radiol 47:451-456

89. Berrington de Gonzalez A, Kim KP, Knudsen AB et al (2011) Radiation-related cancer risks from CT colonography screening: a risk-benefit analysis. AJR Am J Roentgenol 196:816-823

90. Boellaard TN, Venema HW, Streekstra GJ et al (2012) Effective radiation dose in CT colonography: is there a downward trend? Acad Radiol 19:1127-1133

91. Chang KJ, Caovan DB, Grand DJ et al (2013) Reducing radiation dose at CT colonography: decreasing tube voltage to $100 \mathrm{kVp}$. Radiology 266:791-800

92. Park SK, Park DI, Lee SY et al (2009) Extracolonic findings of computed tomographic colonography in Koreans. World J Gastroenterol 15:1487-1492

93. Yee J, Kumar NN, Godara S et al (2005) Extracolonic abnormalities discovered incidentally at CT colonography in a male population. Radiology 236:519-526

94. Chin M, Mendelson R, Edwards J et al (2005) Computed tomographic colonography: prevalence, nature, and clinical significance of extracolonic findings in a community screening program. Am J Gastroenterol 100:2771-2776

95. Veerappan GR, Ally MR, Choi JH et al (2010) Extracolonic findings on CT colonography increases yield of colorectal cancer screening. AJR Am J Roentgenol 195:677-686

96. Macari M, Nevsky G, Bonavita J et al (2011) CT colonography in senior versus nonsenior patients: extracolonic findings, recommendations for additional imaging, and polyp prevalence. Radiology 259: 767-774

97. Kim YS, Kim N, Kim SY et al (2008) Extracolonic findings in an asymptomatic screening population undergoing intravenous contrast-enhanced computed tomography colonography. J Gastroenterol Hepatol 23:e49-57

98. Pickhardt PJ, Hanson ME, Vanness DJ et al (2008) Unsuspected extracolonic findings at screening $\mathrm{CT}$ colonography: clinical and economic impact. Radiology 249:151-159 
99. Flicker MS, Tsoukas AT, Hazra A et al (2008) Economic impact of extracolonic findings at computed tomographic colonography. J Comput Assist Tomogr 32:497-503

100. Gluecker TM, Johnson CD, Wilson LA et al (2003) Extracolonic findings at CT colonography: evaluation of prevalence and cost in a screening population. Gastroenterology 124:911-916

101. Sonnenberg A, Delco F, Bauerfeind P (1999) Is virtual colonoscopy a cost-effective option to screen for colorectal cancer? Am J Gastroenterol 94:2268-2274

102. Hewitson P, Glasziou P, Irwig L et al (2007) Screening for colorectal cancer using the faecal occult blood test, Hemoccult. Cochrane Database Syst Rev 1, CD001216. doi:10.1002/14651858. CD001216.pub2

103. Kuipers EJ, Rosch T, Bretthauer M (2013) Colorectal cancer screening - optimizing current strategies and new directions. Nat Reviews Clin Oncol 10:130-142

104. Wilschut JA, Hol L, Dekker E et al (2011) Cost-effectiveness analysis of a quantitative immunochemical test for colorectal cancer screening. Gastroenterology 141:1648-1655, e1641

105. Heresbach D, Djabbari M, Riou F et al (2011) Accuracy of computed tomographic colonography in a nationwide multicentre trial, and its relation to radiologist expertise. Gut 60:658-665

106. Liedenbaum MH, van Rijn AF, de Vries AH et al (2009) Using CT colonography as a triage technique after a positive faecal occult blood test in colorectal cancer screening. Gut 58:1242-1249

107. Liedenbaum MH, de Vries AH, van Rijn AF et al (2010) CT colonography with limited bowel preparation for the detection of colorectal neoplasia in an FOBT positive screening population. Abdom Imaging 35:661-668

108. Sali L, Falchini M, Della Monica P et al (2010) CT colonography before colonoscopy in subjects with positive faecal occult blood test. Preliminary experience. Radiol Med 115:1267-1278

109. Lansdorp-Vogelaar I, van Ballegooijen M, Zauber AG et al (2009) At what costs will screening with CT colonography be competitive? A cost-effectiveness approach. Int J Cancer 124:1161-1168

110. Sali L, Grazzini G, Ventura L et al (2013) Computed tomographic colonography in subjects with positive faecal occult blood test refusing optical colonoscopy. Dig Liver Dis 45:285-289

111. Plumb AA, Halligan S, Nickerson C et al (2013) Use of CT colonography in the English Bowel Cancer Screening Programme. Gut 63:964-973

112. Manfredi S, Bouvier AM, Lepage $C$ et al (2006) Incidence and patterns of recurrence after resection for cure of colonic cancer in a well defined population. Br J Surg 93:1115-1122

113. Schoemaker D, Black R, Giles L et al (1998) Yearly colonoscopy, liver $\mathrm{CT}$, and chest radiography do not influence 5-year survival of colorectal cancer patients. Gastroenterology 114:7-14

114. Rex DK, Kahi CJ, Levin B et al (2006) Guidelines for colonoscopy surveillance after cancer resection: a consensus update by the American Cancer Society and the US Multi-Society Task Force on Colorectal Cancer. Gastroenterology 130: 1865-1871

115. Kobayashi H, Mochizuki H, Sugihara K et al (2007) Characteristics of recurrence and surveillance tools after curative resection for colorectal cancer: a multicenter study. Surgery 141:67-75

116. Kim HJ, Park SH, Pickhardt PJ et al (2010) CT colonography for combined colonic and extracolonic surveillance after curative resection of colorectal cancer. Radiology 257:697-704

117. Fletcher JG, Johnson CD, Krueger WR et al (2002) Contrastenhanced CT colonography in recurrent colorectal carcinoma: feasibility of simultaneous evaluation for metastatic disease, local recurrence, and metachronous neoplasia in colorectal carcinoma. AJR Am J Roentgenol 178:283-290

118. Laghi A, Iannaccone R, Bria E et al (2003) Contrast-enhanced computed tomographic colonography in the follow-up of colorectal cancer patients: a feasibility study. Eur Radiol 13:883-889
119. Leonardou P, Striggaris K, Pappas P et al (2006) Screening of patients after colectomy: virtual colonography. Abdom Imaging 31:521-528

120. You YT, Chang Chien CR, Wang JY et al (2006) Evaluation of contrast-enhanced computed tomographic colonography in detection of local recurrent colorectal cancer. World J Gastroenterol 12: $123-126$

121. Amitai MM, Fidder H, Avidan B et al (2009) Contrast-enhanced CT colonography with 64-slice MDCT compared to endoscopic colonoscopy in the follow-up of patients after colorectal cancer resection. Clin Imaging 33:433-438

122. Neri E, Vagli P, Turini F et al (2010) Post-surgical follow-up of colorectal cancer: role of contrast-enhanced CT colonography. Abdom Imaging 35:669-675

123. Lee JH, Park SH, Lee SS et al (2011) CT colonography in patients who have undergone sigmoid colostomy: a feasibility study. AJR Am J Roentgenol 197:W653-657

124. Hassan C, Quintero E, Dumonceau JM et al (2013) Postpolypectomy colonoscopy surveillance: European Society of Gastrointestinal Endoscopy (ESGE) Guideline. Endoscopy 45: $842-851$

125. Colquhoun P, Chen HC, Kim JI et al (2004) High compliance rates observed for follow up colonoscopy post polypectomy are achievable outside of clinical trials: efficacy of polypectomy is not reduced by low compliance for follow up. Colorectal Dis 6:158-161

126. Taylor DP, Cannon-Albright LA, Sweeney C et al (2011) Comparison of compliance for colorectal cancer screening and surveillance by colonoscopy based on risk. Genet Med 13:737-743

127. Rapuri S, Spencer J, Eckels D (2008) Importance of postpolypectomy surveillance and postpolypectomy compliance to follow-up screeningreview of literature. Int J Colorectal Dis 23:453-459

128. Cooper GS, Kou TD, Barnholtz Sloan JS et al (2013) Use of colonoscopy for polyp surveillance in Medicare beneficiaries. Cancer 119:1800-1807

129. Khan JSKJS, Moran BJ (2011) Iatrogenic perforation at colonic imaging. Colorectal Dis 13:481-493

130. Berrington de Gonzalez A, Kim KP, Yee J (2010) CT colonography: perforation rates and potential radiation risks. Gastrointest Endosc Clin N Am 20:279-291

131. Atalla MA, Rozen WM, Master M et al (2009) Education and Imaging. Colonic perforation during 'virtual' CT colonography. J Gastroenterol Hepatol 24:1800

132. Regge D, Neri E, Turini F et al (2009) Role of CT colonography in inflammatory bowel disease. Eur J Radiol 69:404-408

133. Wong SH, Wong VWS, Sung JJY (2007) Virtual colonoscopyinduced perforation in a patient with Crohn's disease. World J Gastroenterol 13:978-979

134. Belo-Oliveira P, Curvo-Semedo L, Rodrigues H et al (2007) Sigmoid colon perforation at CT colonography secondary to a possible obstructive mechanism: Report of a case. Dis Colon Rectum 50:1478-1480

135. Coady-Fariborzian L, Angel LP, Procaccino JA (2004) Perforated colon secondary to virtual colonoscopy: Report of a case. Dis Colon Rectum 47:1247-1249

136. Triester SL, Hara AK, Young-Fadok TM et al (2006) Colonic perforation after computed tomographic colonography in a patient with fibrostenosing Crohn's disease. Am J Gastroenterol 101:189 192

137. Young BM, Fletcher JG, Earnest F et al (2006) Colonic perforation at $\mathrm{CT}$ colonography in a patient without known colonic disease. AJR Am J Roentgenol 186:119-121

138. Debugne G, Gillet B, Pierard S et al (2006) [Colonic perforation after virtual colonoscopy]. [Article in French.]. Gastroenterol Clin Biol 30:1103-1105 
139. Ganesh S, Pathma-Nathan N, Loder P (2009) Colonic perforation from computed tomographic colonography: A real complication from a virtual procedure. Surgical Practice 13:58-59

140. Bassett JT, Liotta RA, Barlow D et al (2008) Colonic perforation during screening $\mathrm{CT}$ colonography using automated $\mathrm{CO} 2$ insufflation in an asymptomatic adult. Abdom Imaging 33:598-600

141. Hassan C, Pickhardt PJ, Kim DH et al (2010) Systematic review: distribution of advanced neoplasia according to polyp size at screening colonoscopy. Aliment Pharmacol Ther 31:210-217

142. Rex DK, Kahi C, O’Brien M et al (2011) The American Society for Gastrointestinal Endoscopy PIVI (Preservation and Incorporation of Valuable Endoscopic Innovations) on real-time endoscopic assessment of the histology of diminutive colorectal polyps. Gastrointest Endose 73:419-422

143. Hoff G, Foerster A, Vatn MH et al (1986) Epidemiology of polyps in the rectum and colon. Recovery and evaluation of unresected polyps 2 years after detection. Scand J Gastroenterol 21:853-862

144. Hofstad B, Vatn MH, Andersen SN et al (1996) Growth of colorectal polyps: redetection and evaluation of unresected polyps for a period of three years. Gut 39:449-456

145. Hisabe T, Tsuda S, Matsui T et al (2010) Natural history of small colorectal protuberant adenomas. Dig Endosc 22(Suppl 1):S43-46

146. Pickhardt PJ, Hain KS, Kim DH et al (2010) Low rates of cancer or high-grade dysplasia in colorectal polyps collected from computed tomography colonography screening. Clin Gastroenterol Hepatol 8: 610-615

147. Pickhardt PJ, Kim DH, Pooler BD et al (2013) Assessment of volumetric growth rates of small colorectal polyps with CT colonography: a longitudinal study of natural history. Lancet Oncol 14:711-720

148. Kolligs FT, Crispin A, Graser A et al (2013) Risk factors for advanced neoplasia within subcentimetric polyps: implications for diagnostic imaging. Gut 62:863-870

149. Lieberman D, Moravec M, Holub J et al (2008) Polyp size and advanced histology in patients undergoing colonoscopy screening: implications for CT colonography. Gastroenterology 135:1100 1105

150. Taylor SA, Slater A, Burling DN et al (2008) CT colonography: optimisation, diagnostic performance and patient acceptability of reduced-laxative regimens using barium-based faecal tagging. Eur Radiol 18:32-42

151. Lefere PA, Gryspeerdt SS, Dewyspelaere J et al (2002) Dietary fecal tagging as a cleansing method before CT colonography: initial results polyp detection and patient acceptance. Radiology 224: 393-403

152. Hixson LJ, Fennerty MB, Sampliner RE et al (1991) Prospective blinded trial of the colonoscopic miss-rate of large colorectal polyps. Gastrointest Endosc 37:125-127

153. Pickhardt PJ, Nugent PA, Mysliwiec PA et al (2004) Location of adenomas missed by optical colonoscopy. Ann Intern Med 141: 352-359

154. Rex DK, Overhiser AJ, Chen SC et al (2009) Estimation of impact of American College of Radiology recommendations on CT colonography reporting for resection of high-risk adenoma findings. Am J Gastroenterol 104:149-153
155. Gupta N, Bansal A, Rao D et al (2012) Prevalence of advanced histological features in diminutive and small colon polyps. Gastrointest Endosc 75:1022-1030

156. Bose M, Bell J, Jackson L et al (2007) Virtual vs. optical colonoscopy in symptomatic gastroenterology out-patients: the case for virtual imaging followed by targeted diagnostic or therapeutic colonoscopy. Aliment Pharmacol Ther 26:727-736

157. Cotton PB, Durkalski VL, Pineau BC et al (2004) Computed tomographic colonography (virtual colonoscopy): a multicenter comparison with standard colonoscopy for detection of colorectal neoplasia. JAMA 291:1713-1719

158. Fisichella VA, Jaderling F, Horvath S et al (2009) Primary threedimensional analysis with perspective-filet view versus primary two-dimensional analysis: evaluation of lesion detection by inexperienced readers at computed tomographic colonography in symptomatic patients. Acta Radiol 50:244-255

159. Hoppe H, Netzer P, Spreng A et al (2004) Prospective comparison of contrast enhanced CT colonography and conventional colonoscopy for detection of colorectal neoplasms in a single institutional study using second-look colonoscopy with discrepant results. Am J Gastroenterol 99:1924-1935

160. Kalra N, Suri S, Bhasin DK et al (2006) Comparison of multidetector computed tomographic colonography and conventional colonoscopy for detection of colorectal polyps and cancer. Indian J Gastroenterol 25:229-232

161. Laghi A, Iannaccone R, Carbone I et al (2002) Computed tomographic colonography (virtual colonoscopy): blinded prospective comparison with conventional colonoscopy for the detection of colorectal neoplasia. Endoscopy 34:441-446

162. Munikrishnan V, Gillams AR, Lees WR et al (2003) Prospective study comparing multislice CT colonography with colonoscopy in the detection of colorectal cancer and polyps. Dis Colon Rectum 46: $1384-1390$

163. Ozsunar Y, Coskun G, Delibas N et al (2009) Diagnostic accuracy and tolerability of contrast enhanced CT colonoscopy in symptomatic patients with increased risk for colorectal cancer. Eur J Radiol 71:513-518

164. Pfeifer GK (2008) Corleta O, Gus P [Evaluation of computed tomographic colonography for detection of colorectal polyps]. [Article in Portuguese.]. Arq Gastroenterol 45:301-307

165. Regge D, Galatola G, Martincich L et al (2000) Use of virtual endoscopy with computerized tomography in the identification of colorectal neoplasms. Prospective study with symptomatic patients. Radiol Med 99:449-455

166. Roberts-Thomson IC, Tucker GR, Hewett PJ et al (2008) Singlecenter study comparing computed tomography colonography with conventional colonoscopy. World J Gastroenterol 14:469-473

167. Taylor SA, Halligan S, Saunders BP et al (2003) Use of multidetector-row CT colonography for detection of colorectal neoplasia in patients referred via the Department of Health "2Week-wait" initiative. Clin Radiol 58:855-861

168. Vogt C, Cohnen M, Beck A et al (2004) Detection of colorectal polyps by multislice CT colonography with ultra-low-dose technique: comparison with high-resolution videocolonoscopy. Gastrointest Endosc 60:201-209 